\title{
Estimation of Trawl Door Spread from Wing Spread
}

\author{
P. J. G. Carrothers \\ Department of Fisheries and Oceans, Marine Fish Division \\ Biological Station, St. Andrews, New Brunswick, Canada EOG 2X0
}

\begin{abstract}
A simplified analytical method is presented and demonstrated for estimating trawl door spread from trawl construction data and accurate information on trawl wing spread. Trawl door spread is a factor in gear catchability.
\end{abstract}

\section{Introduction}

Trawl spread is frequently used in the quantification of fishing effort exerted by a trawl during a tow, expressed either as area of seabed swept or as volume of water filtered. Usually the spread of the wing tips is used, even though some fish may escape over the headline and under the footrope. However, the ground warps (sweeps or cables) between the wing tips and the trawl doors have a definite herding effect by driving fish into the path of the net. The most convincing evidence of this is that virtually all commercial trawls are now fitted with ground warps which result in increased catches, whereas at one time the trawl doors were attached to the wing tips. Treschev (1978) recognized the increased efficiency of trawls with ground warps by defining the active region of a trawl to include not only the area in the path of the footrope but also the areas in the path of the ground warps and wing bridles (Fig. 1).

It is technically difficult but possible to measure the spread of the wing tips using hydroacoustic instruments. Such measurements are usually done during calibration tows, as the instruments interfere with the setting and hauling of the trawl during fishing tows. However, it is very impractical to measure the spread of the trawl doors, even during calibration tows.

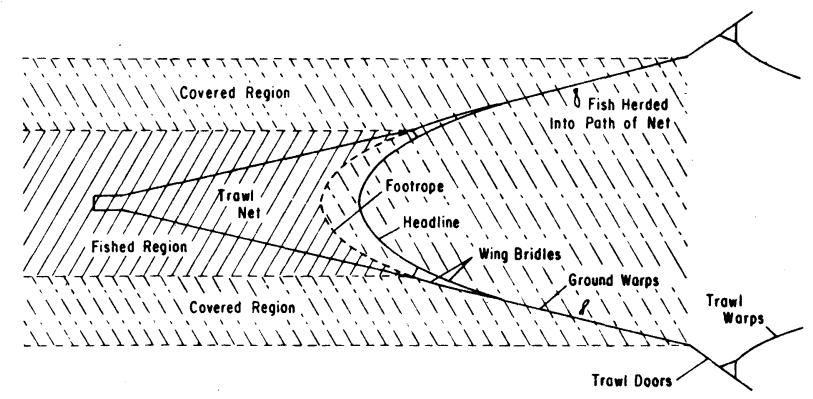

Fig. 1. The active region of a groundfish trawl.
This was done by Crewe (1964) but the instruments were cumbersome. Any instruments attached to groundfish trawl doors are vulnerable, and any data link from the doors to the trawl or to the vessel is very exposed to damage. The alternative is to estimate door spread from measurements taken at the net or at the vessel.

Estimation of door spread from wing spread is basically an exercise in curve fitting. The trawl headline, footrope, wing bridles (legs) and ground warps (sweeps) are flexible cables whose shapes are governed by the equilibrium of forces on them and tensions in them. The procedure is to find, deductively, mathematical planforms and profiles for these cables which most closely satisfy these loading conditions. Crewe (1964) reported that a catenary fitted to the center two-thirds of the headline, with tangential straight lines to the doors, fitted his experimental measurements adequately. This was probably true for the relatively short wing bridles and ground warps on trawls used by the United Kingdom fleet at that time, but hydrodynamic drag on the cables generates curvature so that Crew's (1964) method results in an overestimate of door spread in Canadian trawls. J. J. Foster (personal communication, 1967) indicated that, as a first approximation, researchers at the Marine Laboratory, Aberdeen, Scotland, sometimes fit the catenary to the full headline length and extrapolate the linear tangent from the wing tips to the doors. This results in a more realistic estimate of door spread for long ground warps than does the Crewe method, but the method is rather crude and does not specifically account for various curvatures resulting from different ground warp lengths, diameters and tensions.

The hydrodyamics of wire rope has been studied quite extensively both for the United States Navy (Landweber and Protter, 1944) and for the Canadian Navy (Eames, 1967), particularly in relation to 
TABLE 1. Measured dimensions of groundfish otter trawls and estimated trawl door spreads. (All spreads and lengths, including catenary parameters are in feet, $1 \mathrm{ft}=0.3048 \mathrm{~m}$; warp diameters are in inches, 1 in $=25.4 \mathrm{~mm} ; \mathrm{SD}=$ standard deviation.)

\begin{tabular}{|c|c|c|c|c|c|c|c|c|c|c|c|c|c|c|c|}
\hline \multirow[b]{3}{*}{ Trawl characteristics } & \multirow{2}{*}{\multicolumn{2}{|c|}{$\begin{array}{c}\quad\left(H_{s}\right) \\
\text { Wing spread } \\
\end{array}$}} & \multirow{3}{*}{$\begin{array}{c}\left(H_{L}\right) \\
\text { Headline } \\
\text { length }\end{array}$} & \multirow{3}{*}{$\begin{array}{l}\left(S_{L}\right) \\
\text { Wing } \\
\text { bridle } \\
\text { length }\end{array}$} & \multirow{2}{*}{\multicolumn{2}{|c|}{$\begin{array}{c}\quad\left(S_{G}\right) \\
\text { Ground warp } \\
\end{array}$}} & \multirow{2}{*}{\multicolumn{2}{|c|}{$\begin{array}{c}\text { (Aw) } \\
\text { Catenary } \\
\text { parameter } \\
\end{array}$}} & \multirow{3}{*}{$\begin{array}{l}\text { (Ds) } \\
\text { Est. door } \\
\text { spread }\end{array}$} & \multicolumn{4}{|c|}{ Door spread from } & \multirow{3}{*}{$\begin{array}{c}\text { Tow } \\
\text { numbers }\end{array}$} & \multirow{3}{*}{$\begin{array}{l}\text { Data } \\
\text { points } \\
\text { for } \\
\text { spread }\end{array}$} \\
\hline & & & & & & & & & & \multicolumn{2}{|c|}{ Net data } & \multicolumn{2}{|c|}{ Ves. data } & & \\
\hline & Mean & SD & & & Length & Diam. & Mean & SD & & Mean & $\overline{S D}$ & Mean & $\overline{S D}$ & & \\
\hline Engel 145-ft, high-lift, oval door, no kite & 45.8 & 3.3 & 96 & 164 & 120 & 0.880 & 1200 & 90 & 191 & 198 & 20 & 149 & 17 & $1-2$ & 9 \\
\hline Engel 145-ft, high-lift, oval doors, with kite & 46.5 & 3.7 & 96 & 164 & 120 & 0.880 & 1432 & 89 & 194 & 203 & 22 & 177 & 19 & 3 & 5 \\
\hline Engel $145-\mathrm{ft}$, high-lift, rect. doors, with kite & 48.2 & 0.8 & 96 & 164 & 120 & 0.880 & 1209 & 171 & 205 & 213 & 5 & 158 & 8 & 4 & 6 \\
\hline Engel $145-\mathrm{ft}$, high-lift, rect, doors, no kite & 51.4 & 1.3 & 96 & 164 & 120 & 0.880 & 1329 & 255 & 226 & 233 & 8 & 166 & 8 & 5 & 7 \\
\hline Engel $145-\mathrm{ft}$, high-lift, instruments on rect. doors & 50.4 & 0.8 & 96 & 164 & 120 & 0.880 & 979 & 256 & 217 & 222 & 5 & 169 & 31 & $6-7$ & 16 \\
\hline West Coast, polythene, instruments on rect. doors & 42.5 & 0.4 & 77 & 91 & 120 & 0.750 & 1041 & 168 & 177 & 183 & 2 & 209 & 16 & $8-9$ & 13 \\
\hline Yankee 41, high-lift, instruments on rect. doors & 44.2 & 0.3 & 78 & 90 & 30 & 0.875 & 1021 & 204 & 127 & 129 & 1 & 124 & 11 & $10-11$ & 14 \\
\hline Yankee 35, polythene & 27.5 & 1.4 & 52 & 30 & 90 & 0.500 & 619 & 83 & 100 & 100 & 7 & 102 & 6 & $13-16$ & 21 \\
\hline Yankee 36 , polythene & 33.3 & 1.7 & 60 & 30 & 120 & 0.625 & 647 & 44 & 131 & 131 & 9 & 121 & 10 & $17-18$ & 5 \\
\hline Yankee 41, polythene, 7-in discs. 36-fm fishing depth & 42.5 & 0.8 & 79 & 31 & 180 & 0.875 & 779 & 116 & 171 & 173 & 4 & 178 & 10 & $19-22$ & 29 \\
\hline Yankee 41, polythene, 18-in rollers, 36 -fm fishing depth & 40.8 & 1.1 & 79 & 31 & 180 & 0.875 & 705 & 81 & 163 & 163 & 6 & 172 & 11 & $23-26$ & 31 \\
\hline Yankee 41 , polythene, 18 -in rollers, 47 -fm fishing depth & 44.9 & 0.9 & 79 & 31 & 180 & 0.875 & 725 & 66 & 186 & 187 & 6 & 182 & 28 & $27-28$ & 18 \\
\hline Yankee 41 , poly braid, 21 -in rollers, 180 -ft sweeps & 42.7 & 1.1 & 79 & 31 & 180 & 0.875 & 707 & 82 & 173 & 173 & 6 & 185 & 11 & $29-33$ & 35 \\
\hline Yankee 41, poly briad, 21 -in rollers, 120 -ft sweeps & 45.9 & 1.1 & 79 & 31 & 120 & 0.875 & 775 & 157 & 153 & 153 & 5 & 160 & 6 & $35-36$ & 14 \\
\hline Yankee 41, poly briad, Dan Leno gear. 21 -in rollers & 46.5 & 0.7 & 79 & 7 & 138 & 0.875 & 760 & 213 & 151 & 147 & 3 & 173 & 5 & $37-39$ & 16 \\
\hline Yankee 41 , treated nylon, 18 -in rollers, 90 -ft sweeps & 44.4 & 1.2 & 79 & 31 & 90 & 0.875 & 762 & 96 & 125 & 127 & 5 & 144 & 9 & $40-43$ & 21 \\
\hline Yankee 41 , polythene, 18 -in rollers, $43 \mathrm{ft}^{2}$ rect. doors & 47.0 & 1.7 & 79 & 31 & 180 & 0.875 & 731 & 69 & 200 & 200 & 11 & 185 & 22 & $44-47$ & 27 \\
\hline Yankee 41, polythene, 18 -in rollers, $30 \mathrm{ft}^{2}$ oval doors & 44.5 & 2.3 & 79 & 31 & 180 & 0.875 & 682 & 71 & 182 & 184 & 14 & 194 & 20 & $48-51$ & 34 \\
\hline Yankee 41, polypropylene, 18 -in rollers, $43 \mathrm{ft}^{2}$ rect. doors & 46.2 & 1.7 & 79 & 31 & 180 & 0.875 & 703 & 91 & 193 & 195 & 11 & 198 & 25 & $52-55$ & 28 \\
\hline Yankee 41 , polypropylene, 18 -in rollers, $30 \mathrm{ft}^{2}$ oval doors & 44.7 & 2.6 & 79 & 31 & 180 & 0.875 & 675 & 91 & 185 & 187 & 16 & 195 & 29 & $57-59$ & 25 \\
\hline Skagen, poly braid, rounded, 120 -ft legs, $180-\mathrm{ft}$ sweeps & 40.8 & 1.8 & 82 & 120 & 180 & 0.875 & 642 & 95 & 199 & 204 & 12 & 229 & 14 & $64-68$ & 39 \\
\hline Granton, polythene, 21 -in rollers, $120-\mathrm{ft}$ sweeps & 43.3 & 1.2 & 79 & 31 & 120 & 0.875 & 792 & 95 & 140 & 137 & 5 & 167 & 9 & $70-71$ & 12 \\
\hline Atl. Western III, 21 -in rollers, $90-\mathrm{ft}$ legs, $180-\mathrm{ft}$ sweeps & 35.6 & 2.2 & 79 & 91 & 180 & 0.875 & 987 & 247 & 162 & 165 & 14 & 141 & 21 & $72-75$ & 30 \\
\hline
\end{tabular}

minesweeping gear. Analytical mathematical models of varying complexity have been developed. One of these describes the planform of a towed wire rope, secured at both ends, as a catenary whose parameter is a function of the tension in the line, its diameter and the hydrodynamic pressure. In the analysis of data from an engineering study of groundfish trawls, Carrothers (unpublished) fitted one wire-rope catenary to the ground warps, other catenaries to the upper and lower wing bridles and wing ends of the headrope and footrope, and further catenaries to the bights of the headrope and the footrope. The starboard and port sides of the trawl were treated separately to account for asymmetry of the trawl. This method produced the door-spread estimates given as 'door spread from net data' in Table 1. It requires measurements of headline wing spread, wing bridle tensions, hydrodynamic pressure at the trawl, and the diameters and lengths of all cables.

The method presented in this paper for estimating trawl door spread from headline wing spread as the only measured dimension is a simplified version of the above-noted method. It has been applied to trawl data from the engineering study, with the results given as 'estimated door spread' in Table 1 for comparison with the more rigorous method. Also, for comparison, the door spreads calculated by means of trawl warp analysis from measurements taken at the vessel during the engineering study are listed as 'door spread from vessel data' in Table 1. More detailed characteristics of the trawls listed in Table 1 have been previously reported by Carrothers et al. (1969). For the mean values given in Table 1, only data for hydrodynamic pressures between 25 and 70 pounds per square foot (1.20 to $3.35 \mathrm{kPa}$ ), corresponding to normal towing speeds between 3 and 5 knots ( 1.5 to $2.6 \mathrm{~m} / \mathrm{sec}$ ), were used.

\section{Description of the Method}

The simplified method for estimating trawl door spread from wing spread first assumes that the trawl is symmetrical in planform so that only one half of the trawl needs to be considered. One line catenary is fitted to the ground-warp, upper wing leg and the forward one-eighth of the headline, and another catenary is fitted to the bight of the headline, as shown in Fig. 2. The two catenaries are tangential where they touch one another.

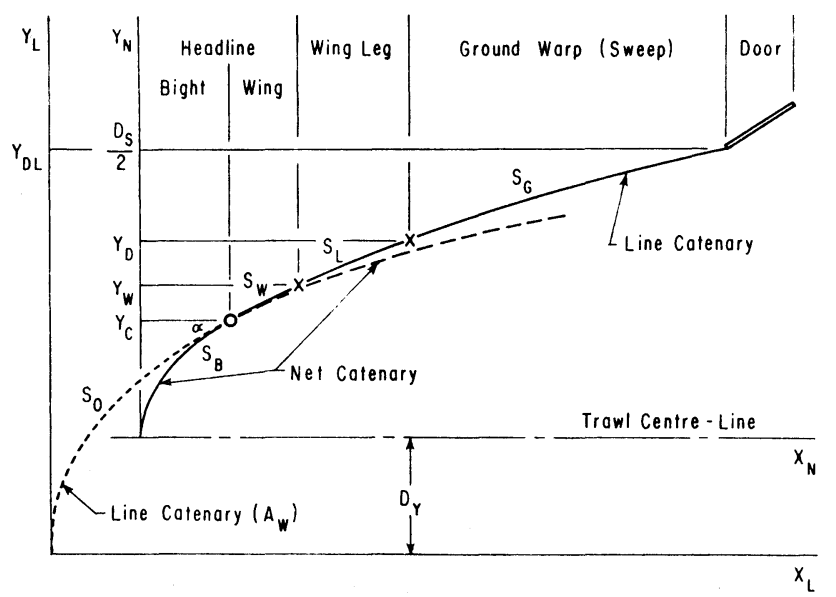

Fig. 2. Trawl line planform geometry. (See text for definitions of coded parameters.) 
The input data required are:

$$
\begin{aligned}
& H_{S}=\text { headline wing spread }=2 Y_{W} \\
& H_{L}=\text { headline length }=2\left(S_{B}+S_{W}\right) \\
& S_{L}=\text { upper wing leg (bridle) length } \\
& S_{G}=\text { groundwarp (sweep) length } \\
& A_{W}=\text { wire-rope catenary parameter. }
\end{aligned}
$$

The headline wing spread needs to be measured, for example, by net sounder transducers mounted, facing inward, on the headline wing tips during a calibration tow, as described by Crewe (1964), Carrothers (1968), French (1968), and Acker and Brune (1974). The three length measurements can be taken from the trawl specifications. The wire-rope catenary parameter must be 'guessed', but considerations for this are discussed in the next section. As shown in Fig. 3, the door spread estimate is relatively insensitive to bad 'guesses' of this catenary parameter but it is quite sensitve to errors in wing spread, a $5 \%$ error in wing spread causing a $7 \%$ error in door spread estimate.

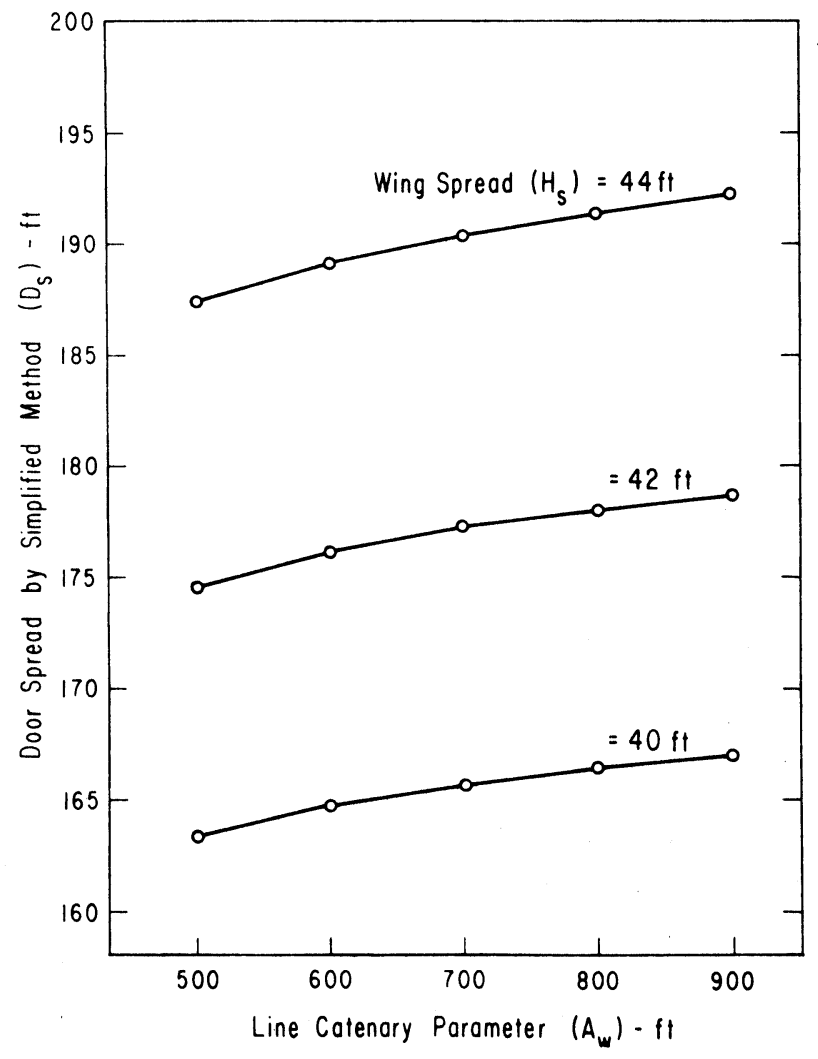

Fig. 3. Effect of errors in headline wing spread measurement and ground-warp catenary parameter estimate on door spread, for Yankee 41 polythene trawl with 7-inch disc footrope, with parameters as listed on line 10 of Table 1.
The procedure for estimating the spread of the trawl doors consists of the following eight steps:

1. Calculate the length of the headline bight catenary as

$$
\mathrm{S}_{\mathrm{B}}=0.375 \mathrm{H}_{\mathrm{L}}
$$

2. Calculate the length of the wing end of the headline as

$$
\mathrm{S}_{\mathrm{W}}=0.125 \mathrm{H}_{\mathrm{L}}
$$

3. Calculate the offset of the headline wing tip from the trawl center-line as

$$
Y_{w}=0.5 \mathrm{H}_{s}
$$

4. Calculate the cotangent of the angle of incidence $(\alpha)$ of the headline at the point of contact of the two catenaries from

$$
C_{A}=\sinh \left[\left(1-\frac{S_{B}}{A_{W} C_{A}}\right) \sinh ^{-1}\left(C_{A}\right)+\frac{Y_{W}}{A_{W}}\right]-\frac{S_{W}}{A_{W}}
$$

which can be done iteratively by the subroutine given in Appendix 1.

5. Calculate the distance of the center-line of the wire-rope catenary from the trawl center-line as

$$
D_{Y}=\left[A_{W}-\frac{S_{B}}{C_{A}}\right] \cdot \ln \left(C_{A}+\sqrt{C_{A}^{2}+1}\right)
$$

6. Calculate the door offset variable from

$$
Z_{D}=C_{A}+\left(S_{W}+S_{L}+S_{G}\right) / A_{W}
$$

7. Calculate the offset of the door from the wire-rope catenary center-line from

$$
Y_{D L}=A_{W} \cdot \ln \left(Z_{D}+\sqrt{Z_{D}^{2}+1}\right)
$$

8. Calculate the door spread from

$$
D_{S}=2\left(Y_{D L}-D_{Y}\right)
$$

Derivations of the equations used in this simplified method for estimating door spread are given in Appendix 2.

\section{The Ground Warp Catenary Parameter}

The wire-rope or line catenary parameter $\left(A_{W}\right)$ 
(Fig. 2) is a measure of the curvature of the ground warp, a high value representing little curvature (nearly straight) and a low value representing considerable curvature. Increased line tensions tend to straighten the ground warp and increase $A_{w}$, whereas increased drag acting across the line tends to bend the ground warp and decrease $A_{w}$. Analytically, this parameter is given by

$$
A_{w}=\frac{T}{C_{N} \phi q}
$$

where $\mathrm{T}=$ tension in the line

$$
\mathrm{C}_{\mathrm{N}}=\text { drag coefficient for wire rope when at }
$$
right angles to the fluid flow $(\simeq 1.4)$

$\phi=$ diameter of ground warp in the same length unit as for $A_{w}$ (e.g. meters)

and $\quad \mathrm{q}=0.5 \rho \mathrm{V}^{2}=$ hydrodynamic pressure at the trawl

where $\rho=$ mass density of sea water $(\simeq 1025 \mathrm{~kg} /$ $\mathrm{m}^{3}$ if $\mathrm{q}$ in Newtons, or $\simeq 105 \mathrm{kgf}-\mathrm{S}^{2} / \mathrm{m}^{4}$ if $q$ in $\mathrm{kgf} / \mathrm{m}^{2}$ )

and

$$
V=\text { trawl speed through the water }
$$

From this equation and as confirmed by experimental evidence (Fig. 4), anything added to the trawl which increases the drag, such as a heavier footrope (Yankee trawls), a headline kite (Engel trawl), thicker netting twines or smaller meshes, increases the line tension $(T)$ and consequently also increases the catenary parameter $\left(A_{w}\right)$. Also, a smaller ground-warp diameter relative to trawl drag (Engel vs Yankee increases $A_{w}$, as indicated in the engineering study (Table 1, Fig. 4).

The means and standard deviations for the ground-warp catenary parameter $\left(A_{w}\right)$ are presented in Table 1 as a guide to indicate the approximate magnitude of this parameter for use in estimating the door spread of new trawls comparable to those used in the engineering study. The ground-warp diameters are also listed to facilitate adjustments to the catenary parameter $\left(A_{w}\right)$ for different warp sizes, using the above equation.

An increase in the towing speed results in an increase in both the trawl drag (and hence groundwarp tension) and the hydrodynamic pressure at about the same rate, so that there is relatively little change in the ground-warp catenary parameter over the normal range of towing speeds. To be more precise, as towing speed increases, the increasing drag of the upper portion of the net forces the headline down and back so

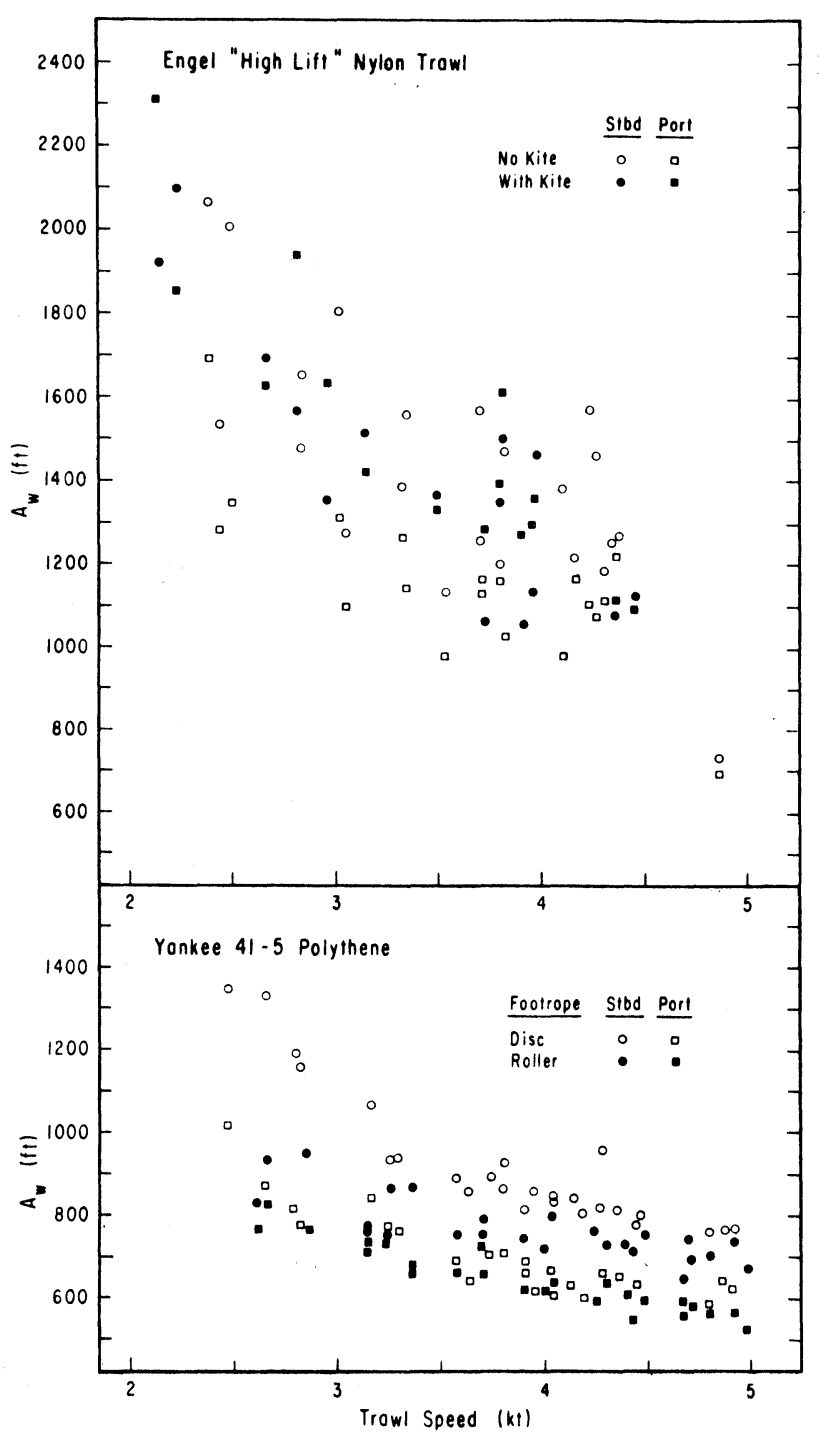

Fig. 4. Experimental ground-warp catenary valves plotted against towing speed for the Engel and Yankee 41 groundfish trawls.

that the drag of the trawl as a whole increases somewhat more slowly with towing speed than does the hydrodynamic pressure, and this results in the slightly negative correlation shown in Fig. 4.

It is significant to note that the difference between the ground-warp catenary parameters for the port and starboard sides of the trawl (Fig. 4), caused by crosscurrents, is of the same order of magitude as differences caused by minor trawl appendages or normal changes in towing speed. Considering that perturbations in the catenary parameter $\left(A_{w}\right)$ do not seriously affect the door-spread estimate, there should be no difficulty in intuitively estimating adequately accurate values for the ground-warp catenary parameter. 


\section{Conclusion}

The spread of trawl doors, as required for adequate interpretation of the fishing characteristics of trawls, can be estimated with reasonable accuracy from measurements of the frame lines and working lines of the trawl and accurate information on the wing spread under conditions of interest, thus avoiding the difficult process of trying to measure the trawl-door spread with instruments.

\section{Acknowledgements}

Thanks are extended to D. N. Fitzgerald for processing the data for Table 1 and Fig. 3, and to P.W. G. McMullon for preparing the illustrations.

\section{References}

ACKER, W. C., and F. A. BRUNE. 1974. Electroacoustic measurement of trawl parameters. In: Proc. IEEE International Conference
'Ocean 74: Engineering in the Ocean Environment,' Vol. II, p. 55-57.

CARROTHERS, P. J. G. 1968. Instrumentation for the engineering study of otter trawls. Bull. Fish. Res. Bd. Canada, No. 163, 45 p. MS 1979. The effect of load distribution on the mathematical planforms of trawl frame lines. ICES C.M. Doc. 1979/B:2.

CARROTHERS, P. J. G., P. J. FOULKES, M. P. CONNORS, and A. G. WALKER. 1969. Data on the engineering performance of Canadian east coast groundfish otter trawls. Fish. Res. Bd. Canada Tech. Rept, No. 125, 108 p.

CREWE, P. R. 1964. Some of the general engineering principles of trawl gear design. In: Modern Fishing Gear of the World 2, Fishing News (Books) Ltd., London, England, p. 165-180.

EAMES, M. C. 1967. Steady-state theory of towing cables. Defence Research Establishment Atlantic, Dartmouth, N. S., Canada, Rept. $67 / 5,20 \mathrm{p}$

FRENCH, L. E. 1968. Sonic system for determining distances between selected points of an otter trawl. U. S. Fish. WildI. Serv., Fish. Ind. Res., 4(3): 113-125.

LANDWEBER, L., and M. H. PROTTER. 1944. The shape and tension of a light, flexible cable in a uniform current. U. S. Navy, David W. Taylor Model Basin, Washington, D. C., Rept. No. 533, 33 p.

TRESCHEV, A. I. 1978. Application of the fished volume method for measuring fishing effort. ICES Coop. Res. Rept., No. 79, 54 p. 


\section{Appendix 1}

\section{Computer Program for Estimating Door Spread by the Simplified Method}

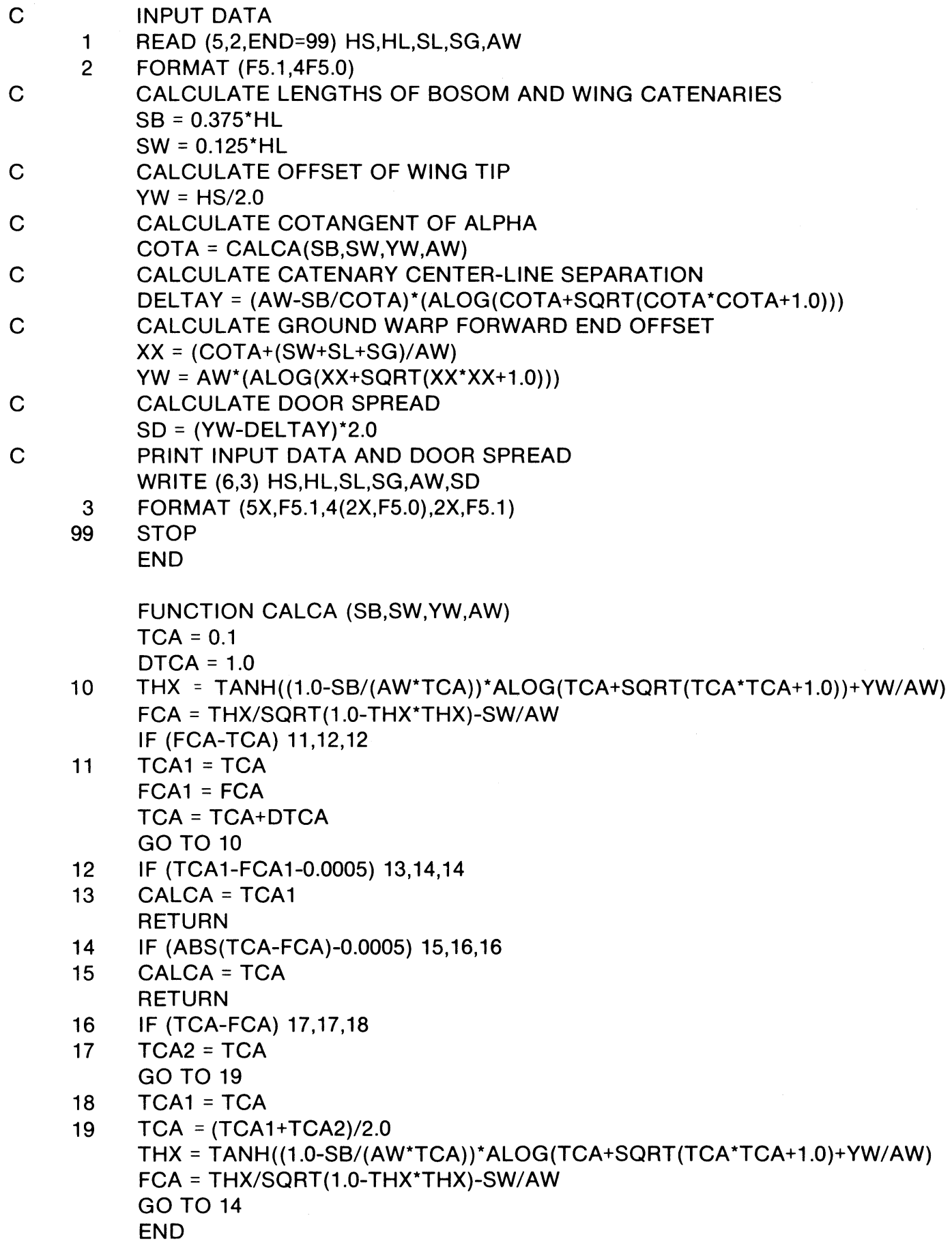




\section{Appendix 2}

\section{Derivation of Equations Used in the Simplified Method for Estimating Door Spread}

It can be shown (Carrothers, MS 1979) that the bight of the trawl headline can be adequately represented by a catenary of the form

$$
X_{N}=A_{N}\left(\cosh \left(Y_{N} / A_{N}\right)-1\right)
$$

where $X_{N}=$ distance ahead of the headline bosom

$$
\begin{aligned}
& Y_{N}=\text { distance to port or starboard from the trawl center-line } \\
& A_{N}=T /\left(C_{N} \phi_{N} q\right) \\
& T \quad=\text { headline tension at the trawl center-line }
\end{aligned}
$$

$\mathrm{C}_{\mathrm{N}} \phi_{\mathrm{N}}=$ effective hydrodynamic diameter of the loaded headline

and $\quad \mathrm{q} \quad=$ hydrodynamic pressure at the trawl (see equation (5) below).

From the properties of the catenary, the angle of incidence $\left(\alpha_{N}\right)$ of the headline to the direction of tow at any point in this bight is given by

$$
\cot \left(\alpha_{N}\right)=S_{N} / A_{N}=\sinh \left(Y_{N} / A_{N}\right)
$$

where $S_{N}=$ distance along the headline bight catenary from the trawl center-line.

It can be shown (Carrothers, MS 1979) that the wing of the headline, the upper wing bridle and the ground warp can be adequately represented by a catenary of the form

$$
X_{L}=A_{W}\left(\cosh \left(Y_{L} / A_{W}\right)-1\right)
$$

where $A_{w}=T_{L} /\left(C_{N} \phi q\right)$

$\mathrm{C}_{\mathrm{N}} \approx 1.4$ = hydrodynamic drag coefficient for wire rope with axis normal to the fluid flow

$$
\phi \quad=\text { diameter of the ground warp }
$$

and $\quad \mathrm{q} \quad=0.5 \rho \mathrm{V}^{2}=$ hydrodynamic pressure at the trawl

where $\rho=$ mass density of sea water $\left(\simeq 1025 \mathrm{~kg} / \mathrm{m}^{2}\right.$ if q in Newtons $/ \mathrm{m}^{2}$, or $\simeq 105 \mathrm{kgf}-\mathrm{s}^{2} / \mathrm{m}^{4}$ if $q$ in $\left.\mathrm{kgf} / \mathrm{m}^{2}\right)$ and $\quad \mathrm{V}=$ trawl speed through the water.

As in equation (3), the angle of incidence $\left(\alpha_{L}\right)$ at any point is given by

$$
\cot \left(\alpha_{L}\right)=S_{C} / A_{W}=\sinh \left(Y_{L} / A_{W}\right)
$$

where $S_{C}=$ distance along this line catenary from its origin at the intersection of the $X_{L}$ and $Y_{L}$ axes.

The axes for the line catenary $\left(X_{L}, Y_{L}\right)$ are not coincident with the axes for the head-line bight catenary $\left(X_{N}, Y_{N}\right)$. 
As shown in Fig. 2, the principle of the method is to fit these two catenaries (eq. 1) and (eq. 4) to the known headline length and wing spread, making the two curves tangential at the point of contact and then extrapolating the line catenary (eq. 4) along the upper wing bridle and ground warp to the door in order to estimate the door spread. For present purposes, the trawl is assumed to be symmetrical about its center-line, the $X_{N}$ axis of the headline bight catenary (eq. 1).

From these geometric constraints and the properties of the catenary, it can be shown (Carrothers, MS 1979) that

$$
\cot \alpha=\sinh \left[1-\frac{S_{B}}{A_{W} \cot \alpha} \sinh ^{-1}(\cot \alpha)+\frac{Y_{W}}{A_{W}}\right]-\frac{S_{W}}{A_{W}}
$$

where $\alpha=$ angle of incidence of the headline to the direction of tow at the point of contact of the two catenaries,

$\mathrm{S}_{\mathrm{B}}=$ length of the headline bight catenary (eq. 1) from its origin to the point of contact,

$S_{w}=$ length of the line catenary (eq. 4) from the point of contact to the wing tip,

$\mathrm{Y}_{\mathrm{w}}=$ wing-tip offset from the trawl center-line.

This is the equation solved iteratively for $\mathrm{C}_{\mathrm{A}}=\cot \alpha$ in step 4 of the text.

In the more rigorous method for estimating door spread from trawl-net data (door spread from net data in Table 1), two-thirds of the headline and a similar length of the footrope were assigned to the net catenaries, resulting in the estimate of door spread from net data being only about $3 \%$ higher overall than that from vessel data. However, a similar division of the headline in the simplified method results in the door spread estimate being about $10 \%$ too high. This bias was corrected by assigning three-quarters of the headline to the net catenary. Thus

$$
\mathrm{S}_{\mathrm{B}}=0.375 \mathrm{H}_{\mathrm{L}} \quad \text { and } \quad \mathrm{S}_{\mathrm{W}}=0.125 \mathrm{H}_{\mathrm{L}}
$$

where $H_{L}$ is the known headline length. Also, since the trawl is considered to be symmetrical, the offset of the headline wing tip from the trawl center-line is

$$
\mathrm{Y}_{\mathrm{w}}=\mathrm{H}_{\mathrm{S}} / 2
$$

where $\mathrm{H}_{\mathbf{S}}$ is the measured headline wing-tip spread. These are the equations used in steps 1,2 and 3 of the text.

For the headline bight catenary at the point of contact of the two catenaries, $\cot \alpha_{\mathrm{N}}=\cot \alpha$, as found by eq. (7), and $S_{N}=S_{B}$ and $Y_{N}=Y_{C}$ (Fig. 2). Therefore, from eq. (3)

$$
A_{N}=S_{B} / \cot \alpha
$$

$$
\text { and } \quad Y_{C}=A_{N} \sinh ^{-1}(\cot \alpha)=\frac{S_{B} \sinh ^{-1}(\cot \alpha)}{\cot \alpha}
$$

For the line catenary at the point of contact, $\cot \alpha_{\mathrm{L}}=\cot \alpha$, as founded by eq. (7), and eq. (6) therefore gives

$$
Y_{L}=Y_{C}+D_{Y}=A_{W} \sinh ^{-1}(\cot \alpha)
$$

From equations (10) and (11)

$$
D_{Y}=\left[A_{W}-\frac{S_{B}}{\cot \alpha}\right] \sinh ^{-1}(\cot \alpha)
$$


which is the equation used for step 5 , given the identity

$$
\sinh ^{-1}\left(C_{A}\right)=\ln \left(C_{A}+\sqrt{C_{A}^{2}+1}\right)
$$

Exprapolating the line catenary from the point of contact of the two catenaries to the forward end of the ground warp, at the door $Y_{L}=Y_{D L}$ and $S_{C}=S_{o}+S_{W}+S_{L}+S_{G}$ (Fig. 2), so that eq. (6) gives

$$
Y_{D L}=A_{W} \sinh ^{-1}\left[\frac{S_{O}+S_{W}+S_{L}+S_{G}}{A_{W}}\right]
$$

Since $\alpha_{\mathrm{L}}=\alpha$ and $\mathrm{S}_{\mathrm{C}}=\mathrm{S}_{\mathrm{o}}$ at the point of contact of the two catenaries, equation (6) gives

$$
\mathrm{S}_{\mathrm{o}}=\mathrm{A}_{\mathrm{w}} \cot \alpha
$$

Substituting equation (15) in (14)

$$
Y_{D L}=A_{w} \sinh ^{-1}\left[\cot \alpha+\frac{S_{W}+S_{L}+S_{G}}{A_{W}}\right]
$$

Setting

$$
\mathrm{Z}_{\mathrm{D}}=\cot \alpha+\left(\mathrm{S}_{\mathrm{W}}+\mathrm{S}_{\mathrm{L}}+\mathrm{S}_{\mathrm{G}}\right) / \mathrm{A}_{\mathrm{W}}
$$

to simplify manipulation, eq. (16) and (17) and the identity represented by eq. (13) give the equations used in steps 6 and 7 of the text.

The geometry presented in Fig. 2 indicates that

$$
D_{S}=2\left(Y_{D L}-D_{Y}\right)
$$

which is the equation used for step 8 of the text. 
